\title{
Smart adaptive learning management application
}

\begin{abstract}
Learning systems are learning management systems and are considered a powerful management tool in supporting inclusion for learners with disabilities. Some people with disabilities have to use some kind of assistive technologies to access e-learning content. Each type of disabilities requires certain types of adaptations in the design of e-content. For example, while captions in videos are a necessity for deaf users, audio reading is inevitable for blind ones. Including such technologies into a smart e-learning environment provide huge opportunities to customize the content to needs and ability of disabled learners. In this paper, we propose a Smart Assistive Learning Technology (SALT) system. Based on the user profile that includes the disability type, SALT determines suitable tools and materials for disable learners. A number of learning activities and the corresponding learning style for each activity are defined in SALT system identifies and proposes the supporting learning styles for each commonly known disability. Experimentation results have been shown the system to be efficient for recognizing learner's single disability or multiple disabilities where applicable and identify the associated assistive technologies.
\end{abstract}

Keywords: assistive technologies, eye injuries, hearing damage, personalized learning environment
Volume 6 Issue 5 - 2017

\author{
Ghada Al-Hudhud, Henda Chorfi \\ Department of Information Technology, College of Computer \\ and Information Sciences, King Saud University, KSA
}

Correspondence: Ghada Al-Hudhud PhD SWEng, Department of Information Technology, College of Computer and Information Sciences, King Saud University, Saudi Arabia, Email galhudhud@ksu.edu.sa

Received: November 25, 2017 | Published: December II, 2017
Abbreviations: SALT, smart assistive learning technology, WHO, world health organization

\section{Introduction}

Worker's engagement and concentration are essentials factors for productivity in the workplace. However, busy workers may find it hard to concentrate since their focus can easily distract by many factors and that effects their engagement in work.

According to the World Health Organization (WHO), over a billion people, about $15 \%$ of the world's population, have some form of disability. ${ }^{1}$ The International Classification of Functioning, Disability and Health (ICF) define disability as an umbrella term for impairments, activity limitations and participation restrictions. Despite the huge number of disable people around the world, a UNESCO Global report (UNESCO Global Report, 2013) indicates that people with disabilities face a wide range of barriers, including access to information, education and a lack of job opportunities. However, developing Smart Assistive eLearning Technologies (SALT) can be a powerful tool in supporting education and inclusion for persons with disabilities. The web is nowadays the best illustration. Indeed, the Web is fundamentally designed to work for all people, whatever their hardware, software, language, culture, location, or physical or mental ability. When the Web meets this goal, it is accessible to people with a diverse range of hearing, movement, sight, and cognitive ability. In the same line, the United Nations Convention on the Rights of Persons with Disabilities recognizes access to Information and Communications Technologies, including the Web, as a basic human right. ${ }^{2}$ In accordance with the later convention, the World Wide Web Consortium Web Accessibility Initiative (W3C WAI) brings together people from industry, disability organizations, government, and research labs from around the world to develop guidelines and resources to help make the Web accessible to people with disabilities including auditory, cognitive, neurological, physical, speech, and visual disabilities. ${ }^{3}$

In another side, the evolution of the web helped a lot the evolution of E-Learning. E-learning is the acquisition and use of knowledge distributed and facilitated by electronic means. ${ }^{4}$ For people with disabilities, such way of learning is very advantageous especially when it is personalized and adapted to their needs and taking into account their disabilities. With the growth of technology, this adaptation is nowadays possible. Previous research of adaptive learning for people with disabilities mainly focused on one type of disability. In this paper, an innovative adaptive approach is proposed by basing upon any type of disability. Indeed, we propose a Personalized Learning Environment (PLE) system that deals with different type of disabilities. Based on the user profile that includes the disability type, a number of defined learning activities and the corresponding learning style for each activity, the system identifies and proposes the supporting learning styles for each commonly known disability.

In the following, the next subsection presents the various assistive technologies and their use related to disability type. Thereafter, an overview on Accessible and adaptive learning environment is given. The design of the proposed system is then presented. Afterward, some experimental results are discussed. Finally, we conclude our paper.

\section{Background}

\section{Assistive technologies per type of disability}

Generally, people with disabilities are grouped into four major categories; Table 1:

- Visual Disability (VD): blindness, low vision, color-blindness

- Hearing Disability (HD): people who are deaf and hard-of-hearing have no problems seeing the computer monitor or the TV screen. They have problems with sounds and spoken communication.

- Physical Disability (PD): inability to use a mouse, slow response time, limited fine motor control

- Cognitive Disability (CD): learning disabilities, distractibility, inability to remember or focus on large amounts of information

To access properly the e-learning content, people with disabilities require, in one hand, some types of adaptations in the design of 
the learning content, in the other hand, various kinds of assistive technologies. So how can we define assistive technologies and which assistive technology is appropriate for each disability type? In the following, we will deal with those two questions.

Table I Categories of disability types and commonly known assistive technologies

Category of disability Assistive technology Description

VD, CD, PD

VD, CD, PD

VD, CD

VD, CD

VD

VD

VD

VD

PD

CD

CD

CD
Eye tracking

Speech recognition

Text-to-speech (TTS)

Optical character recognition (OCR)

Refreshable braille display

Braille translation

Audio description

Screen reader

Abbreviation expanders

Alternative keyboards

Freeform database

software
Software that interacts with a computer to present enlarged screen content.

Software that allows people to operate their computer and enter data using voice rather than a mouse or a keyboard.

Software that converts written text such as, text files, web pages, PDFs and emails into audio files that can play on a wide range of devices, such as computers, MP3 players, iPods and CD players.

Software that takes scanned text and converts the scanned image into to an electronic text file, which can be saved and edited.

An electronic device that connects to computers and produces tactile Braille output from what is on-screen.

Software that is used in conjunction with a braille embosser. Electronic documents are loaded into the translation software and can be edited, if necessary, before printing.

A narration track for audio visual content displayed on a television, video, computer or cinema screen, for viewers who wish to access it. It describes what is happening onscreen and utilizes the natural pauses in the audio in order to be unobtrusive

Software that "talks" to the user with synthetic speech. It provides feedback to users to interact with a page.

Device that follows the movement of the eyes and allows the person to navigate through the web with only eye movements.

Software programs allow a user to create, store, and re-use abbreviations for frequently-used words or phrases.

Programmable keyboards having special overlays that customize the appearance and function of a standard keyboard.

A tool that allow the user to create and store electronic notes by "jotting down" relevant information of any length and on any subject. He can later retrieve the information by typing any fragment of the original note.
The Technology Related Assistance Act of 1988 (P.L. 101-407) and the Assistive Technology Act of 1998 (P.L. 105-394) provide a standard definition of assistive technology as "any item, piece of equipment, or product, whether acquired commercially, modified, or customized, that is used to increase, maintain, or improve the functional capabilities of individuals with disabilities."

According to Lewis (1998) assistive technology has two major purposes. "First, it can augment an individual's strengths so that his or her abilities counterbalance the effects of any disabilities. Second, technology can provide an alternate mode of performing a task so that disabilities are compensated for or bypassed entirely". ${ }^{5}$ Indeed, Assistive Technology (AT) can have different meanings to different people according to their perspective. For instance, when it is used in the teaching domain, the term Assistive Technology refers to the adaptations and adjustments provided for the learning content. In the same line, The British Educational Communications and Technology Agency (Becta) defines assistive technology as "the software and technology which helps people with disabilities and special needs to overcome the additional challenges they face in communication and learning". Assistive technology includes devices, tools, hardware, or software, which enable, partially, people with disabilities to use the computer. It presents an alternative way to access the content on screen, command the computer or process data. Specific adjustment software or devices for manipulating the computer include. ${ }^{6}$

After defining the term Assistive technologies, the rest of this section will address the second question "Per disability type, which 
assistive technology is appropriate?" through the table below. In the later, we provide the mostly used assistive technologies per category of disability. We mainly focus on software assistive technology.

\section{Accessible and adaptive learning environment}

A Virtual Learning Environment (VLE) 7 is a web-delivered online learning environment with student tracking and access to a wider range of resources and communication tools. An Adaptive Learning Environment(ALE) is a VLE which adapts to the needs of the individual, combining the traditional teaching method of individualized learning with the advantages of a VLE. ${ }^{8}$ Adaptive Learning Environments are environments personalizing the instructional process on different instructional parameters as: sequence of tasks and task difficulty, time and type of feedback, pace of learning speed, reinforcement plan and others. $^{9-16}$

Personalization is in general performed to accommodate user preferences, requirements or (dis-) abilities. Taking into account user disabilities is more and more established in the recent researches. Indeed, for people with disabilities, ALEs are offering new opportunities for learning experiences. Disable learners can benefit from the capabilities of an ALE in different ways, including the flexibility, the mobility and the ability to take part in various types of online communication. Those capabilities are nowadays benefiting from the rapid development of assistive technologies. Appropriate use of assistive technology in an adaptive learning environment enables all learners to be active participants regardless their differences or disabilities.

In the remaining part of the paper, we propose a system that identifies and proposes the supporting learning styles regarding the disability type of the learner.

\section{Smart assistive elearning \& internet of things (IoT)}

Literature introduced the smart assistive technologies as systems comprise multiple communicating technologies standards and most of them are currently operating in storage towers hosted by cloud space. Meanwhile, IoT paradigm commonly aim at delivering efficient and high-quality smart services, interoperation among various IoT standards. Hence, smart elearning quality of service $(\mathrm{QoS})$ is based significantly on the appropriate storage of current and future users data to achieve efficient access for users. ${ }^{17}$

\section{The design of the proposed model}

The proposed system architecture is composed of the following layers, a data source layer which is the base layer that have all the system data, secondly the processing unit layer that handles all data processing, feature extraction and manipulation, thirdly, the control layer, the layer that handles the control of the capturing device and govern the interaction between the interface layer and the processing unit layer. Finally, the interface layer that functions as the interface for the system. In between each layer there is a security layer that ensures a secure link and correct match in data transfer between the layers (Figure 1).

\section{Data source layer}

This layer forms the base layer that has all the system data:

i. Students personal information: major, level, ii. Disability type: visual, hearing, movement, color blind

iii. Preferences

iv. Courses and associated learning activities

In this layer also, all look up tables will be designed and embed as data source for the purpose of associating each disability type with the relevant assistive application. Table 2 presents the types of defined disabilities in the system and the associated technology being used.

1) Visual disability: three levels of disability with three levels of assistive techniques are defined. For input data, the speech recognition application is required. For receiving the output: screen magnifier, text to speech and screen reader.

2) Movement disability

3) Hearing disability (Table 3 )
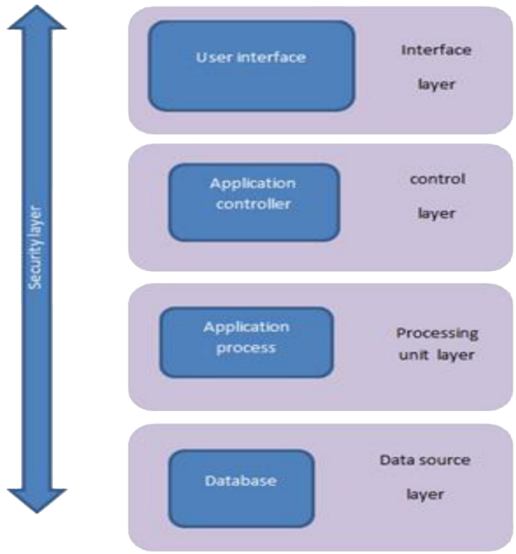

Figure I Architecture of the proposed system.

\section{Processing layer}

This layer will be including all the processing algorithms defined as follows:

I. Student's recognition unit: this unit recognizes the student based on the disability type by taking voice, image or keystroke input and hence identifies the student using voice recognition, face detection, or keyboard/mouse action listener.

II. Profile Creation Unit: this unit presents personal profile items for each user profile that includes: the disability type, a number of defined learning activities and the corresponding learning style for each activity.

III. Assistive Application Recommender Unit: this unit selects the required assistive technology that matches students disability type for each learning.

IV. Matching Unit: this unit maps the profile information to the relevant assistive technology: This unit implements the match algorithm into three levels allowing student interaction for the purpose of accessing the course and a specified learning activity. The first level the student selects course, second level selects activity at the course and the third level identify style. 
Table 2 Identifying the disability types and associated assistive technologies

\begin{tabular}{llll}
\hline Disability type & $\begin{array}{l}\text { Application for passing } \\
\text { input from the user }\end{array}$ & $\begin{array}{l}\text { Application for receiving } \\
\text { output from the system }\end{array}$ & Disability level \\
\hline Visual disability & Speech recognition & $\begin{array}{l}\text { Text to speech } \\
\text { Screen reader }\end{array}$ & Sever visual impairment \\
Visual disability & Speech recognition & $\begin{array}{l}\text { Text to speech } \\
\text { Screen magnifier }\end{array}$ & Medium visual \\
Visual disability & Screen magnifier & Screen magnifier & Weak visual impairment \\
Movement disability & Speech recognition & Text to speech & Sever \\
Movement disability/Visual & Speech recognition & Text to speech & Sever \\
disability & Screen reader & Screen magnifier \\
\hline
\end{tabular}

Table 3 Percentage of recognizing the type/level of disability application for single disability

\begin{tabular}{llll|l|}
\hline Test \# $\begin{array}{l}\text { Testing criteria } \\
\text { for single } \\
\text { disability }\end{array}$ & Yes & $\begin{array}{l}\text { Sometimes not } \\
\text { recognized }\end{array}$ & No & \multicolumn{1}{c}{$\begin{array}{l}\text { Chart interpretation } \\
\text { strongly agree } \\
\text { agree } \\
\text { disagree }\end{array}$} \\
\hline $\begin{array}{l}\text { Disability type } \\
\text { recognized by the } \\
\text { system as one } \\
\text { of the defined } \\
\text { disabilities }\end{array}$ & $75.41 \%$ & $14.75 \%$ & & \\
\hline
\end{tabular}

\section{Control layer}

This layer controls and performs automated check for:

a. User Profile Storage and updates.

b. Reviewing the look up table in terms of using the learning algorithm to record the user experience via back propagation to improve the matching threshold.

c. Match decisions regarding the recommended relevant assistive technology.

d. User interaction and display of the learning contents

\section{How the system works}

Based on the rule that states each virtual user simulates the activity of one real user, the user should start creating new profile for the virtual user (here we've named it Elham1 indicating that the users in this test will only view that site) (Figure 2).

The student then will enter the site URL in the address bar; will display the site inside WAPT where the administrator can navigate through it while the recorder records each step. These steps will be transformed into HTTP request that will be sent to the server (Figure $3)$.
The next step is to call the home page URL and login to the user application using the students credentials and hence the system should launch the required application: for the user Elham it was screen reader. All these steps are recorded and added to the reader's parameters (email, password, and disability type) side where it can be modified later to (elham1@ksu.edu.sa, 123, visual) (Figure 4).

Initially, these parameters will be recorded as static values, they can be used as dynamic values using some of the functions on WAPT. As a result of that, will be able to create different values for each virtual users or even for different sessions (Figure 5).

6. WAPT can also do an automatic parameterization by entering to the settings from "Settings" button, then moving to the parameterization tab (Figure 6):

"WAPT can check all web site responses received during recording for dynamic values located between specified left and right boundaries. When such value is found WAPT creates a variable for it. During the test, the variable will be assigned a value extracted from the actual response using same rules. WAPT will also replace that value in the parameters of all subsequent requests, so that it would be taken from the variable. 


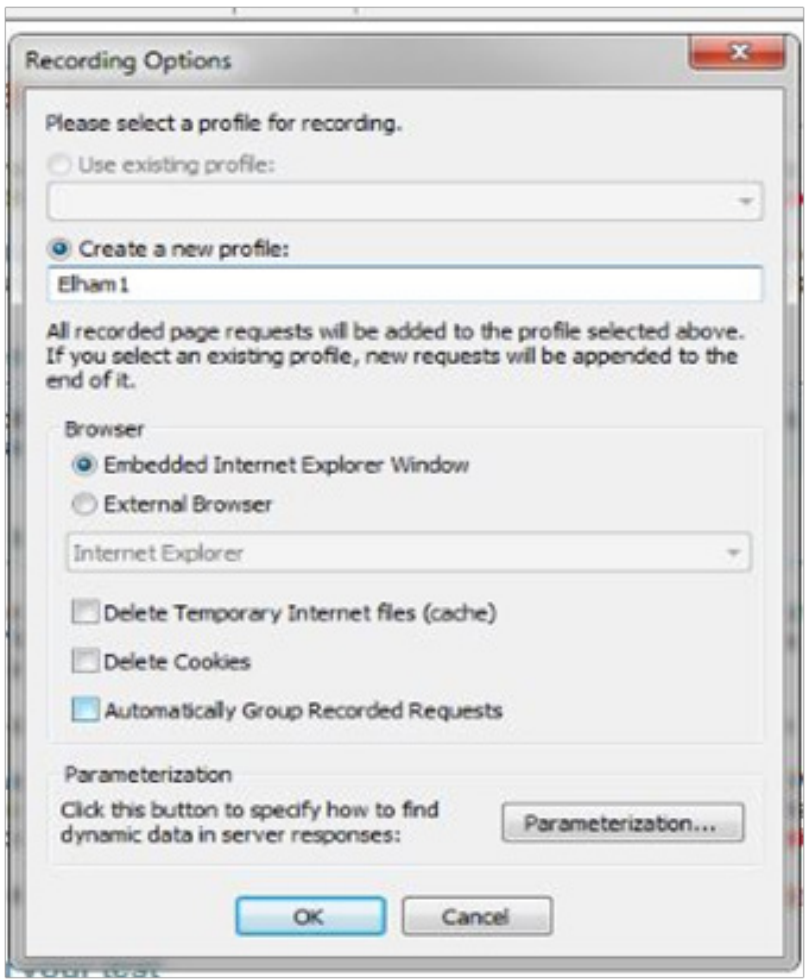

Figure 2 Select profile for recording.

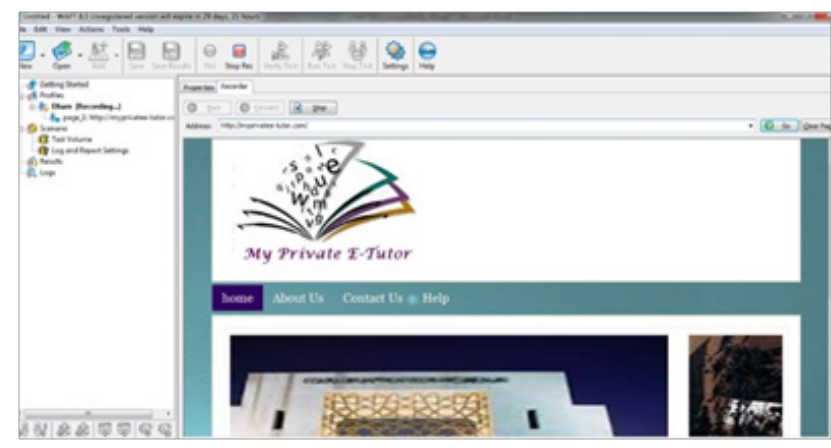

Figure 3 Recording the steps while navigating through myprivatee-tutor.com.

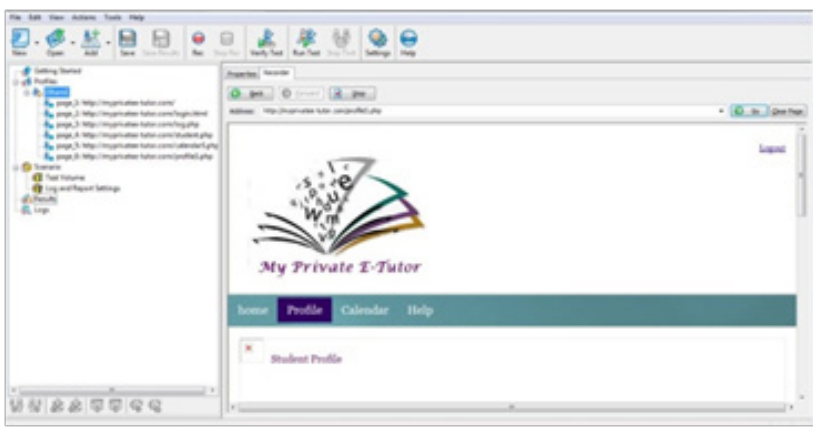

Figure 4 Parameters modification.

\section{Experimentation results}

The system was tested for 120 users, each of the 120 users defined disability type(s). 70 users were defined as single disability; please refer to Table 4, whilst 50 users are defined as with multiple disabilities. The experiment is designed for two stages: first stage is to test the system in terms of recognizing the user and extracting his disability type from the student profile. The second stage is to test the system against selection of the appropriate assistive technology for common types of disabilities.

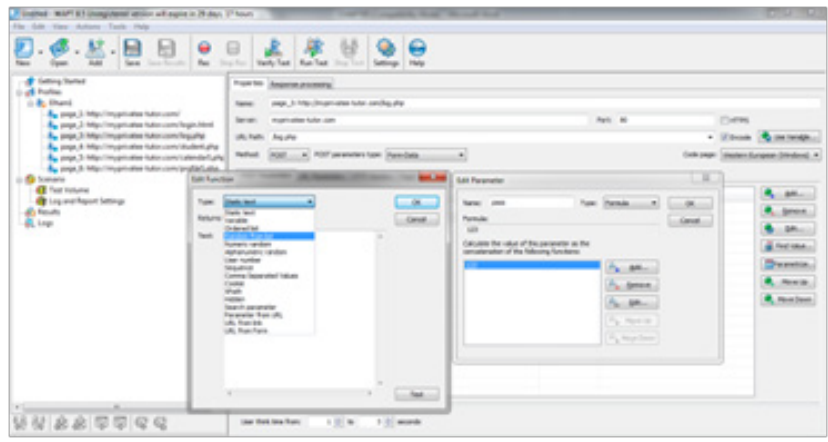

Figure 5 Changing values from static to dynamic.

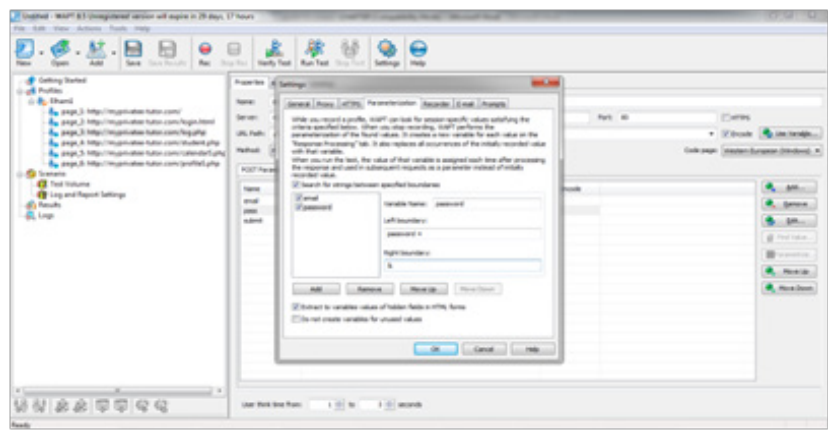

Figure $\mathbf{6}$ automatic parameterization.

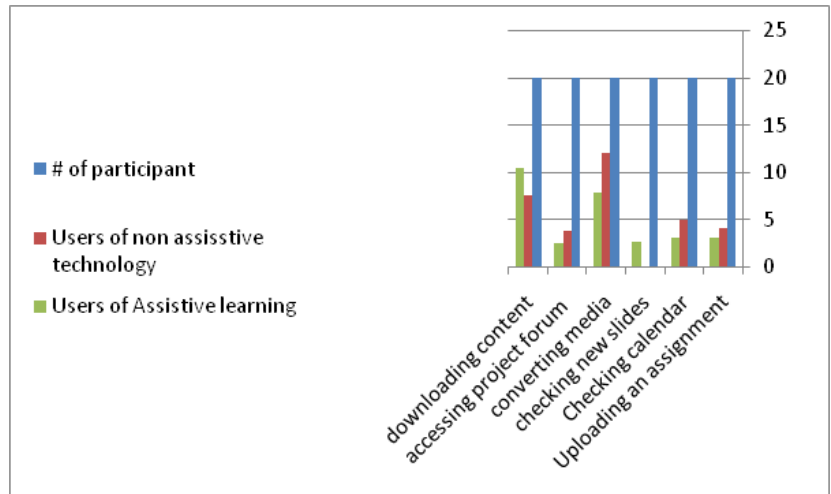

Figure 7 Mental processing time for users of assistive technology in LMS and users of LMS without assistive technology.

A comparison experiment is conducted to compare between the students mental processing time ( using the propose technology and without the proposed technology) in order to complete a task such as uploading and assignment, checking the calendar, converting media file, accessing project forum, and/or downloading a document. The average mental processing time has dropped by $30 \%$ using the assistive LMS over the regular LMS, Figure 7. 
Table 4 Percentage of recognizing the type/level of disability application for multiple disability types

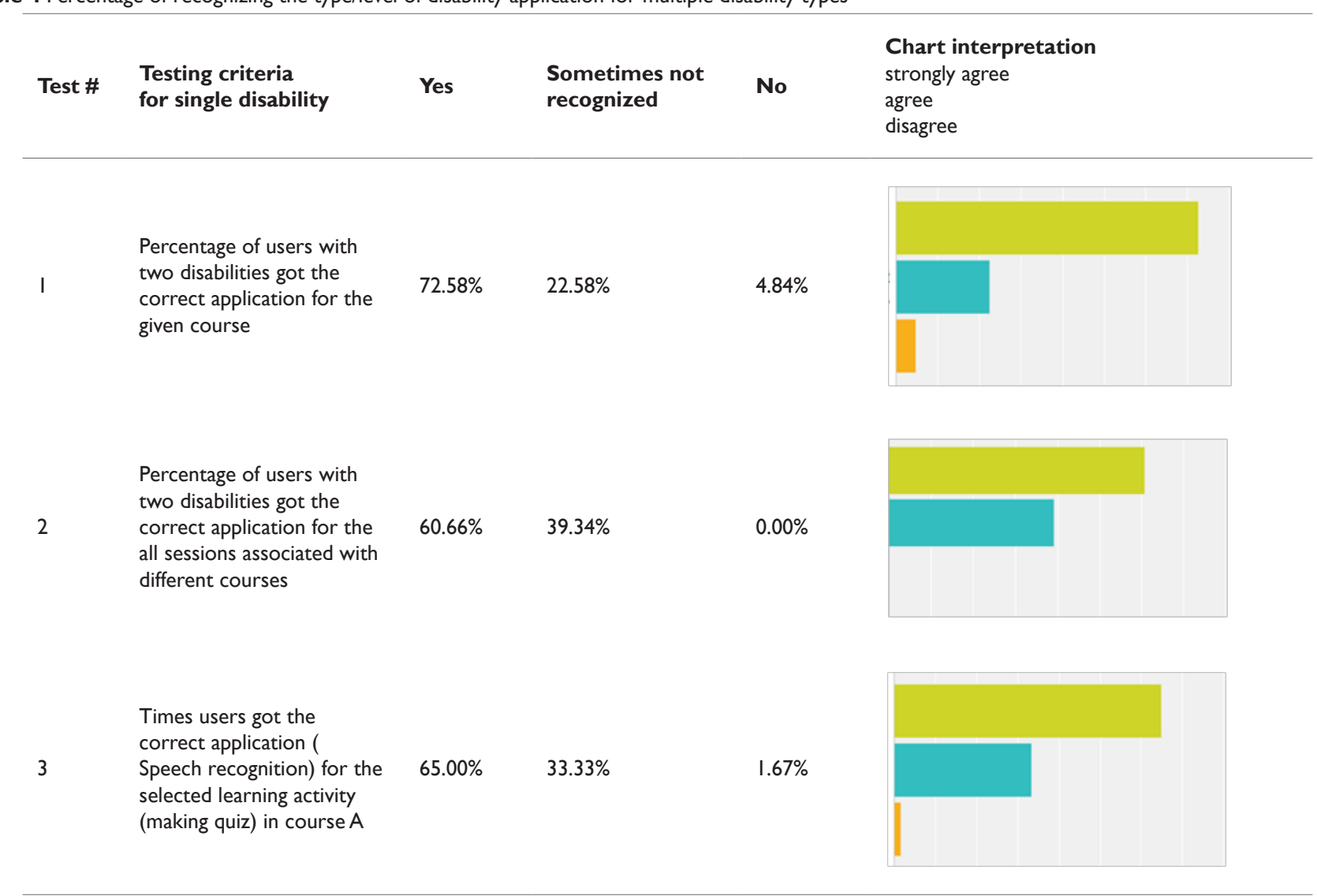

Table 5 Percentage of identifying and match a single disability with correct application

\begin{tabular}{|c|c|c|c|c|c|}
\hline Test \# & $\begin{array}{l}\text { Testing criteria } \\
\text { for single disability }\end{array}$ & Yes & $\begin{array}{l}\text { Sometimes not } \\
\text { recognized }\end{array}$ & No & $\begin{array}{l}\text { Chart interpretation } \\
\text { strongly agree } \\
\text { agree } \\
\text { disagree }\end{array}$ \\
\hline
\end{tabular}

Percentage of sessions course $\mathrm{A}$ launched the correct application

Percentage of students with

2 one disability who got the wrong application during the sessions for course $A$

Percentage of students with one disability who got the applications associated with course $A$ during the sessions for course B
I associated with the users for

$28.33 \%$

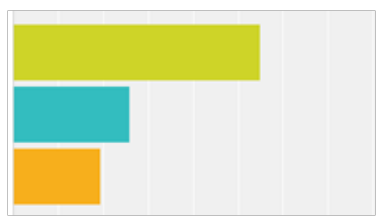

3

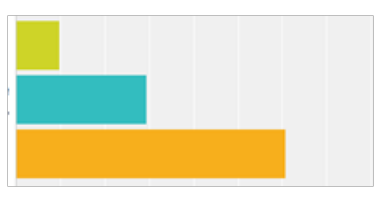

$54.10 \%$

$22.95 \%$

$60.66 \%$

$29.51 \%$

$60.66 \%$

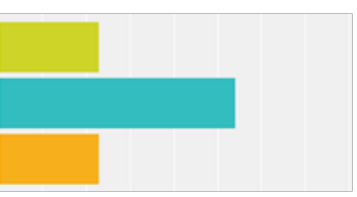


Table 6 Percentage of identifying and match multiple disability types with correct application

\begin{tabular}{|c|c|c|c|c|c|}
\hline Test \# & $\begin{array}{l}\text { Testing criteria } \\
\text { for multiple disability } \\
\text { types }\end{array}$ & Yes & $\begin{array}{l}\text { Sometimes not } \\
\text { recognized }\end{array}$ & No & $\begin{array}{l}\text { Chart interpretation } \\
\text { strongly agree } \\
\text { agree } \\
\text { disagree }\end{array}$ \\
\hline I & $\begin{array}{l}\text { Percentage of students with } \\
\text { hearing/movement disability } \\
\text { who got the associated } \\
\text { applications for course } \\
\text { A launched sessions after } \\
\text { training for } 5 \text { sessions }\end{array}$ & $22.95 \%$ & $54.10 \%$ & $22.95 \%$ & \\
\hline 2 & $\begin{array}{l}\text { Percentage of students } \\
\text { with hearing/movement } \\
\text { disability who got the } \\
\text { wrong application during } \\
\text { the sessions for course } A\end{array}$ & $9.84 \%$ & $29.51 \%$ & $60.66 \%$ & \\
\hline 3 & $\begin{array}{l}\text { Percentage of students } \\
\text { with hearing/movement } \\
\text { disability who got the } \\
\text { applications associated } \\
\text { with course A during the } \\
\text { sessions for course B }\end{array}$ & $58.33 \%$ & $24.33 \%$ & $18.33 \%$ & \\
\hline 4 & $\begin{array}{l}\text { Percentage of students with } \\
\text { visual/movement disability } \\
\text { who got the associated } \\
\text { applications for course } \\
\text { A launched sessions after } \\
\text { training for } 5 \text { sessions }\end{array}$ & $65.00 \%$ & $33.33 \%$ & $1.67 \%$ & \\
\hline 5 & $\begin{array}{l}\text { Percentage of students with } \\
\text { visual/movement disability } \\
\text { who got the wrong } \\
\text { application during the } \\
\text { sessions for course A }\end{array}$ & $58.33 \%$ & $25.00 \%$ & $17.00 \%$ & \\
\hline 6 & $\begin{array}{l}\text { Percentage of students with } \\
\text { visual/movement disability } \\
\text { who got the applications } \\
\text { associated with course } \\
\text { A during the sessions for } \\
\text { course B }\end{array}$ & $58.33 \%$ & $28.33 \%$ & II.33\% & \\
\hline
\end{tabular}

Table 7 Visually impaired tasks duaration in seconds with and without the assistive technology

\begin{tabular}{|c|c|c|c|}
\hline Activity type & $\begin{array}{l}\text { \# of } \\
\text { Participant }\end{array}$ & $\begin{array}{l}\text { Users of } \\
\text { non assistive } \\
\text { technology }\end{array}$ & $\begin{array}{l}\text { Users of } \\
\text { assistive } \\
\text { learning }\end{array}$ \\
\hline $\begin{array}{l}\text { Uploading an } \\
\text { assignment }\end{array}$ & 20 & 4 & 3 \\
\hline $\begin{array}{l}\text { Checking } \\
\text { calendar }\end{array}$ & 20 & 5 & 3 \\
\hline $\begin{array}{l}\text { checking new } \\
\text { slides }\end{array}$ & 20 & & 2.57 \\
\hline converting media & 20 & 12 & 7.9 \\
\hline $\begin{array}{l}\text { accessing project } \\
\text { forum }\end{array}$ & 20 & 3.8 & 2.5 \\
\hline $\begin{array}{l}\text { downloading } \\
\text { content }\end{array}$ & 20 & 7.6 & 10.4 \\
\hline
\end{tabular}




\section{Conclusion \& discussion}

Disabled learners can benefit from the capabilities of an Adaptive Assistive Learning Environment in different ways. Those capabilities are nowadays benefiting from the rapid development of assistive technologies. Appropriate use of assistive technology in an adaptive learning environment enables all learners to experience learning activities regardless their differences or disabilities. The system described in this paper proposes a personalized learning environment that deals with different type of disabilities at two levels: single disability, multiple disabilities. Based on the user profile that includes the disability type, a number of defined learning activities and the corresponding learning style for each activity are defined in the system along with associated techniques to identify and selects the supporting assistive technology for each commonly known disability.

The experimentation results of the proposed system have been proven to be efficient in terms of the both recognition of the disability type of the student; and Table 4 . In the results section Table 5 and Table 6 , the system has been able to recognize after one training session for $60.6 \%$ of the cases of students with single disability whilst $22.95 \%$ of the cases for the multiple disabilities. Hence, in a single disability cases; about $60 \%$ of the students were able to use the correct launched applications and about $58 \%$ for multiple disabilities. The reason for the low percentage regarding recognized disabilities is the insufficient training for the system prior to use. Meanwhile, the user could spend more time on training so that the system could be able to record the required behavior in the user profile.

\section{Biography}

G. Al-Hudhud: This author received her $\mathrm{PhD}$ in the field of controlling multiple mobile cooperative robots from De Montfort University 2005, Leicester, UK. She served as a researcher and lecturer at the same university 2004-2006. She served then at Alahliyya Amman University, Amman, Jordan as a Head of Software Engineering Department 2006-2010. Currently, she serves as associate professor at Department of Information Technology, College of Computer and Information Sciences, King Saud University, Riyadh, KSA. She has several publications in the field of brain computing in the areas of personal identification, multimodal command control systems, and smart office control.

Dr. Al-Hudhud is a professional member in British Computer Society BCS, Association of Computing Machinery. She has earned the best researcher award from Prince Sultan Univesity 6 years ago.

Henda chorfi is currently Assistant Professor at the Information Technology (IT) Department, College of Computer and Information Sciences (CCIS), King Saud University (KSU). Before joining KSU, she was head of the Computer Science Department at ISTMT (University of Tunis El Manar, Tunisia)) and member of the Research Laboratory of Technologies of Information and Communication \& Electrical Engineering (LaTICE, University of Tunis, Tunisia). In the IT department at CCIS, she serves on the Quality and Accreditation Committee. Her Research projects Involvement are e-learning tools and environments, Technology-Enhanced Learning, Adaptive/ Adaptable systems and user modeling. She has published over 40 papers in internationally referred journals and conferences. She serves on program committees and organization committees of numerous international conferences.

\section{Acknowledgements}

The authors extend their appreciation to the Deanship of Scientific Research at King Saud University for funding this work through research group NO (RGP-1438-002).

\section{Conflicts of interest}

None.

\section{References}

1. http://www.who.int/mediacentre/factsheets/fs352/en/

2. http://www.w3.org/standards/webdesign/accessibility

3. http://www.w3.org/WAI/

4. C Holl, L Muilenburg. Supporting Student Collaboration: Edmodo in the Classroom," in Society for Information Technology \& Teacher Education International Conference 2011:3232-3236.

5. Lewis RB. Assistive technology and learning disabilities: Today's realities and tomorrow's promises. Journal of Learning Disabilities. 1998;31(1):16-26.

6. Arrigo M. E-learning Accessibility for blind students. Recent research Developments in Learning Technologies. 2005.

7. G Minshull. Virtual Learning Environment (VLE) Functional Specification, JISC Briefing Paper No.3. London, UK: Joint Information Systems Committee (JISC). 2002.

8. V Carchiolo, A Longheu, M Malgeri. Adaptive Formative Paths in a Web-based learning Environment. Educational Technology \& Society. 2002;5(4):64-75.

9. Specht M. Adaptive Learning Environment. 2012.

10. G Al-hudhud. Intelligent System Design Requirements for personalizing e-Learning Systems: Applications of AI to Education. ISI International Journal of Engineering Education 2012;28(6):1353-1359.

11. ET Welsh, CR Wanberg, KG Brown, et al. E-learning: emerging uses, empirical results and future directions. International Journal of Training and Development. 2003;7(1):245-258.

12. M Drucker, "www. edmodo. com."

13. R Kodzius, D Castro, KC Sumanpreet, et al. Microbead agglutination based assays. 2013.

14. Bongolan R, Moir E, Baron W. Keys to the Secondary Classroom: A Teacher's Guide to the First Months of School: Corwin Press.

15. Avgeriou P, Retalis S, M Skordalakis M. An architecture for open learning management systems," in Advances in Informatics, ed: Springer; 2003:183-200.

16. P Avgeriou, S Retalis, M Skordalakis. Building Quality Into Learning Management Systems-An Architecture-Centric Approach. Advanced Conceptual Modeling Techniques, ed: Springer; 2003:312-324.

17. O Belloa, S Zeadallyb. Toward efficient smartification of the Internet of Things (IoT) services', Future Generation Computer Systems, In Press. 2017. 